\title{
Reconhecimento em Paul Ricoeur: da identificação ao reconhecimento mútuo*
}

\author{
Élsio José Corá ${ }^{1}$ \\ Universidade Federal da Fronteira Sul \\ Cláudio Reichert do Nascimento ${ }^{2}$ \\ Unversidade Federal de Santa Catarina
}

A intenção de Ricoeur (1913-2005) na obra Percurso do Reconhecimento é estabelecer o debate acerca do conceito de reconhecimento, visando constituir um percurso de passagem do reconhecimento como (a) noção epistemológica enquanto identificação, (b) passando pelo o reconhecimento enquanto capacidade antropológica de reconhecimento de si para, finalmente, chegar ao (c) reconhecimento como noção política. Entre os três níveis de reconhecimento supracitados será analisado no decorrer do texto, sobretudo, o aspecto que caracteriza a negação do reconhecimento na filosofia de Hobbes, na qual o indivíduo não é reconhecido pelo o que é, mas segundo os objetivos de sobrevivência. No entendimento de Ricoeur a realidade do estado de natureza (medo, insegurança e desconfiança) descrita na teoria política hobbesiana retarda toda a compreensão relacional do reconhecimento. O presente trabalho aponta que na intenção de estabelecer um reconhecimento mútuo, Ricoeur assinala para um reconhecimento cerimonial pelo dom, marcado pelo relacionamento intersubjetivo.

The intention of Ricoeur (19132005) in the work The Course of Recognition is to establish the debate about the concept of recognition, designed to provide a route for passage of recognition as (a) epistemological notion while identification, (b) the recognition as an anthropological capacity for the recognition of self, to finally, (c) the recognition as a political notion. Among the three levels of recognition we will analyze during the text, the aspect that characterizes the denial of recognition in the Hobbes philosophy, in which the individual is not recognized for what it is, but according to the goals of survival. In understanding of Ricoeur the reality of the nature state (fear, uncertainty and mistrust) described in the hobbesian political theory, slows the whole understanding relational of recognition. The present work shows that in the intention of establishing a mutual recognition, Ricoeur points to a recognition of the gift marked by intersubjective relationship.

\footnotetext{
* Acknowledge on Paul Ricoeur: from identification to mutual recognition

${ }^{1}$ Endereço para correspondências: Rua Acesso Canários da Terra s/n, Seminário, Chapecó, SC, 89813-140 (cora@uffs.edu.br).

${ }^{2}$ Endereço para correspondências: Av. Senador Pinheiro Machado 1953, apto. 02, Centro, São Luiz Gonzaga, RS, 97800-000 (claudioreichertdonascimento@gmail.com).
} 
Palavras-Chave: Reconhecimento - Ricoeur - Hobbes - Hegel - Relacionamento intersubjetivo
Keywords: Acknowledgment - RicoeurHobbes - Hegel - Inter-subjective relationship

\section{Introdução}

Darcours de la reconnaissance (2004), traduzida ao português como "Percurso do reconhecimento" (2006), foi a última obra publicada em vida por Ricoeur. A obra pode ser interpretada como um convite ao autorreconhecimento, de forma analítica e humilde. $\mathrm{O}$ autor estabelece, ainda, o percurso de passagem do reconhecimento como (a) noção epistemológica enquanto identificação, (b) passando pelo o reconhecimento enquanto capacidade antropológica de reconhecimento de si para, finalmente, chegar ao (c) reconhecimento como noção política. Entre os três níveis de reconhecimento supracitados será analisado, sobretudo, o aspecto que caracteriza a negação do reconhecimento na filosofia de Hobbes, na qual o indivíduo não é reconhecido pelo o que ele é, mas segundo os objetivos de sobrevivência.

Sendo assim, o presente artigo discorre sobre o estado de natureza prefigurado por Hobbes e procura apresentar a contrapartida e a ampliação desta pela interpretação ricoeuriana. Além disso, tem-se como pressuposto que, ao usar a expressão "voltar à violência", Ricoeur já pressupõe estarmos fora desse embate de um estado de natureza, prefigurado pelos pensadores contratualistas, representados, principalmente, pela obra de Hobbes. Observa-se que a intenção de Ricoeur, na obra supracitada, é estabelecer um diálogo entre Hobbes e Hegel no que tange ao conceito de reconhecimento. A realidade do estado de natureza descrita, principalmente, na teoria política hobbesiana retarda toda a compreensão relacional do reconhecimento, uma vez que a presença do outro não é necessária e, por sua vez, causa medo, insegurança e desconfiança. Na busca pelo reconhecimento mútuo, Ricoeur aponta para uma possível transformação desse desconhecimento em um reconhecimento mais humano, marcado pelo relacionamento intersubjetivo.

\section{Reflexões acerca do reconhecimento}

No decorrer de sua atividade filosófica, mais de uma vez, Ricoeur recorreu ao léxico das línguas naturais catalogado nos dicionários. Para citar dois exemplos emblemáticos deste artifício, vale lembrar a introdução de Soi-même comme un autre (1990) no qual Ricoeur recupera os termos latinos idem e ipse, frisando que essas expressões encontram e preservam suas correspondências, 
por exemplo, nas línguas inglesa (same, self) e alemão (gleich, Selbst) (RICOEUR, 1990; p. 13). Embora ambos termos latinos signifiquem "o mesmo", há um distinção bastante sutil entre eles e é justamente sobre esta "sutileza", se assim podemos dizer, que Ricoeur propõe a distinção entre o "mesmo" enquanto algo que apresenta uma permanência estrutural e "mesmo" como algo mutável e diverso no tempo. Ao primeiro vai chamar "mesmidade", e ao segundo, ipseidade. Em resumo, o problema da identidade pessoal está relacionado à temporalidade: há algo que permanece o "mesmo" no transcurso do tempo, e há algo que com o transcurso do tempo não permanece o "mesmo", porém sem se tornar "outrem".

Em "Percurso de reconhecimento" (2006), Ricoeur torna a recorrer ao significado de palavras que são usadas no cotidiano e que podem ser fonte de profunda reflexão filosófica. Como ele mesmo dissera em Le conflict des interprétations (1969), os significado das palavras podem apresentar vários sentidos, porém estes não são infinitos.

É o que ocorre com a palavra "reconhecimento". Ricoeur enumera ao menos três sentidos de "reconhecimento", quais sejam: "reconhecimento como identificação", "se reconhecer a si mesmo" e "o reconhecimento mútuo". A partir do estudo do léxico são estipulados três níveis de reconhecimento, que correspondem, esquematicamente, aos três estudos que compõem a obra "Percurso do reconhecimento" (2006). Cada um deles possui uma epígrafe que dá o senso que será abordado em seu decorrer. No primeiro, que trata do reconhecimento como identificação, é citada uma declaração de Pascal, qual seja: “... a essência do equívoco consiste em não o conhecer". No texto em questão, Ricoeur começa sua análise com Descartes e a questão da distinção entre o verdadeiro do falso, talvez para marcar o reconhecimento como identificação formal e não como reinterpretação, como queria Kant, e depois contestá-lo, ao afirmar que um sujeito que duvida por método (obrigação de pensamento) não tem necessidade de distinguir entre o conhecido e o reconhecido (GREISCH, 2006).

Ricoeur (2006) instiga seu leitor a sair do vício cartesiano da dúvida, mas também não considera apropriada a impossibilidade temporal de reconhecimento de Kant ${ }^{3}$. Sua via é a da pluralidade do ser, que muda a cada etapa, a cada novo fato agregado, a cada nova experiência vivida e é esse o pequeno milagre: ser o mesmo em outro, o ser outro em si mesmo. Reconhecer-se não é somente reconhecer-se por meio de algo, por meio de um texto, como queria Proust, ao dizer que o escritor apenas fornece o material imaginário que permite ao leitor descobrir em si mesmo novas facetas que não conhecia, antes de ler o texto,

\footnotetext{
3 "Em nós, algo de Hegel venceu algo de Kant, mas algo de Kant venceu Hegel, porque somos tão radicalmente pós-hegelianos como somos pós-kantianos. Do meu ponto de vista, é esta permuta e esta troca recíproca que estruturam ainda o discurso filosófico hoje. É por isso que a tarefa consiste em pensá-los sempre melhor, pensando-os em conjunto, um contra o outro e um pelo outro" (RICOEUR, 1969; p. 403).
} 


\section{HUMANAS}

e às quais não teria acesso sem ele. $\mathrm{O}$ irreconhecível nem sempre quer dizer desfiguração, degeneração. Também é possível ter que reconhecer algo que se transfigurou, atitude que foi necessária aos apóstolos do Cristo Ressuscitado, que, num primeiro momento, não the reconheceram, tendo que analisar os fatos para chegar ao entendimento de que estavam ante algo conhecido (RICOEUR, 2006).

Seguindo a análise de Greisch (2006), no segundo estudo, a epígrafe é uma frase de Rimbaud: "reconheci-me como poeta". Da mesma maneira, Ricoeur se reconhece filósofo. O reconhecimento de si mesmo, em Ricoeur, parte da filosofia grega, embora para estes a questão do "si mesmo" nunca tenha sido motivo de grandes tratados. Ricoeur (2006) se detém especialmente sobre as fórmulas verbais do reconhecimento, o papel das marcas de reconhecimento e dos disfarces, por meio de grandes obras clássicas, como, por exemplo, a "Odisséia" e "Édipo em Colono". Nessas obras ele encontra não apenas os signos e a semiótica do reconhecimento, como também o potencial do reconhecimento como agente transformador. Nesse sentido, reconhecer é também aceitar e, a partir daí, obter uma nova perspectiva, uma nova dimensão antes não imaginada. Nesse sentido, o sofrimento de Agamenon caracteriza antes uma lição de autorreconhecimento que uma lição de sabedoria.

O reconhecimento de si possibilita uma sabedoria prática, na qual o homem que se conhece pode recorrer a qualquer momento, fazendo-se capaz. A existência de um homem capaz não pressupõe, porém, a existência de um homem incapaz, mas, sim, a existência de quem é capaz e para que ele é capaz. Percebe-se, ainda, que o homem afirma-se e atesta-se como sujeito corpóreo, de carne e osso, capaz de se designar, de agir, de narrar a história da sua vida e de se apresentar e assumir como autor responsável pelos seus atos (SALDANHA, 2009).

No texto intitulado L'Ethique, entre le mal et le pire, Ricoeur esclarece e justifica sua insistência na noção do homem capaz, uma vez que é nessa noção que reside o caráter respeitável do ser humano. $\mathrm{O}$ autor identifica que se vive em uma sociedade em que as pessoas são medidas pelo desempenho e não por suas capacidades. Além disso, percebe-se que muitos são impedidos pela sociedade, pela vida, pela doença, de participar ativamente da sociedade. Com efeito, o que Ricoeur pretende é alcançar o homem capaz, ao invés do homem ineficaz e impotente (J'essaie de rejoindre ce que j'appelle "l'homme capable", derrière "l'homme inefficace", derrière "l'homme impuissant" - RICOEUR, 1994; p. 9).

O papel da memória e da promessa, nesse caminho de reconhecimento, é fundamental, pois a tarefa do conhecimento exige esforço e desejo. Conforme Saldanha (2009) diferentemente de Soi-mêmme comme un autre, em Parcours de la reconnaissance, o autor acrescenta, além da lista das quatro capacidades, as da memória (capacidade de se recordar), e da promessa (capacidade de cumprir o prometido). Ricoeur projeta em conjunto estas duas formas de reconhecimento de si que, apesar de contrárias, uma vez que a memória, 


\section{Reconhecimento em Paul Ricoeur: da identificação ao reconhecimento mútuo}

É.J. Corá \& C.R. do Nascimento

por ser retrospectiva, está voltada para o passado e a promessa, sendo prospectiva, esta voltada para o futuro. Assim, apesar de se colocarem diferentemente na dialética da mesmidade e da ipseidade, conferem ao reconhecimento de si, toda a sua amplitude temporal. Nesse sentido, afirma Saldanha:

Na verdade, fundado tanto numa história de vida,
como em compromissos e expectativas futuras, tal
reconhecimento proporciona-nos uma imagem do
si-mesmo na sua distensão temporal para o passa-
do (memória) e para o futuro (a promessa), mas en-
raizado num presente entendido como presença e
como iniciativa (SALDANHA, 2009; p. 162).

O terceiro estudo da obra, Parcours de la reconnaissance (2004), inicia com uma frase de Rousseau:

[...] Assim que um homem foi reconhecido por outro homem como um Ser senciente, pensante e semelhante a ele, o desejo ou a necessidade de comunicar-lhe os próprios sentimentos e pensamentos fez com que este procurasse os meios de fazer isso" (RICOEUR, 2006; p. 161).

O que se percebe é que não há uma aposta na tese da reciprocidade total, pois, para tanto, em primeiro lugar é preciso que o outro seja análogo ao eu, para que uma nova experiência se inicie com base na reciprocidade, nem tampouco na proposição de Levinas, do outro como um pólo, distinto e reconhecível, mas sempre reduzido a seu irredutível aspecto exterior, realmente o outro como um estrangeiro, que se permite conhecer/reconhecer, mas permanece estrangeiro. Esse dilema vai além da alteridade e permeia o próprio conhecimento de si mesmo: como é difícil se amar, humildemente, se amar (RICOEUR, 2006).

A questão do reconhecimento de si permeia interpretações mais profundas que aquelas relativas à dinâmica do ser. Ela desafia, por exemplo, as soluções da origem do estado de direito propostas por Hobbes e por Hegel. Nesse sentido, para Hobbes, essa seria a via natural para conter o melhor e o pior dos homens; para o Hegel seria a moral, que não é natural, mas torna esse natural possível.

Existe uma necessidade latente de reconhecer e de reconhecer-se como homem que funda o estado de direito, gerando, assim, uma nova via que, de certa maneira, dá a dimensão histórica. Neste momento o diálogo se expande até Hegel, que sempre tentou, rigorosamente, diferenciar e definir o caminho feito pelo espírito na trilha de reconhecer-se para, em seguida, reconhecer e aceitar o outro, dando aí origem ao estado constituído. 


\section{HUMANAS}

Talvez a principal questão levantada por essa nova via seja até que ponto é possível aceitar (reconhecer) o outro sem nos conhecermos totalmente, uma vez que nunca atingimos o conhecimento absoluto de nós mesmos.

Nesse sentido, no texto que se segue pretende-se abordar o tema do desconhecimento originário, bem como a luta pelo reconhecimento, sob o ponto de vista ricoeuriano.

\section{O desconhecimento originário}

O tema do "desconhecimento originário" é tema observado por Hegel em sua teoria do reconhecimento, fazendo referência à teoria do estado de natureza de Hobbes. Este, por sua vez, foi o precursor da filosofia política moderna. A teoria política de Hobbes pode ser tomada diferentemente do ponto de vista dos antigos e dos medievais. Pode-se dizer que a preocupação do relacionamento moral entre indivíduo e cidade recebe uma nova interpretação.

De acordo com Jervolino (1996b) é necessário estabelecer uma ligação entre o esforço por existir e o desejo de uma vida realizada. Essa ligação, no nosso entendimento, serve de base para a defesa de que é necessária uma profunda compreensão da existência como subjetividade, como finitude e, por outro lado, a ameaça constante de falta de sentido que a mesma carrega. É essa possibilidade de compreensão que assegura a abertura de compromisso para a realização e o desejo de uma vida boa, com e para os outros em instituições justas. Appelons visée éthique la visée de la vie bonne avec et pour autrui dans des institutions justes (RICOEUR, 1990; p. 202).

$\mathrm{O}$ tema ético aparece no discurso ricoeuriano tendo em vista que a leitura ética do sujeito também parece ser inconsistente com o traço individualista da subjetividade moderna, acentuadamente egoísta, narcísica e solipsista. Nessas concepções de filosofia, o outro sempre é tomado como problema, sendo apresentado como objeto e não como um assunto de estruturação profunda. Assim, o sujeito que está fechado em si e que pretende governar o mundo, acaba reduzindo o outro a mero objeto. Em contrapartida, tem-se uma percepção do outro como dolorosa e ameaçadora, o que potencializa o surgimento da violência.

A intenção de nosso trabalho justifica-se tendo em vista o que está expresso na frase: homo homini lupus bellum omnium contra omnes. Percebese, com isso, que a violência do homem contra o outro homem, além de ser uma verdade de fato, também é uma verdade de direito. Um dos pressupostos deste estudo será verificar se o reconhecimento pode ser corretamente formado no próprio sentido da subjetividade, trabalhado por Ricoeur, em relação a Hobbes.

Ricoeur (2006) retoma a obra de Hegel, principalmente, a relativa ao período de Iena, visando nomear qual é o adversário que a filosofia política buscou combater e excluir, isto é: o Hobbes do "Leviatã". Nesse sentido, 
acentua Ricoeur (2003), que a idéia de Hobbes, relativa ao conceito de estado de natureza, é uma espécie de fábula da origem que, ademais é perfeitamente reconstruída por meio de uma descrição empírica do estado das coisas. Resta aos homens o medo da morte violenta pela mão do outro. Assim, as paixões que dominam esse medo são a competição, a desconfiança e a glória. O intento ricoeuriano é examinar a ideia de reconhecimento como réplica inversa do estado de desconfiança e como meio de sair do estado de natureza que é apresentado por Hobbes.

Lembra-se que não se tem a pretensão de demonstrar os fatores que permitem afirmar de que maneira a política hobbesiana pode ser tomada de modo diversa dos antigos. Pretender fazê-lo implicaria visitar autores e comentadores sobre esse tema que possibilitam dizer como essa abordagem é feita, bem como apontar em que sentido essa preocupação do reconhecimento moral entre indivíduo e cidade recebe uma nova interpretação em Hobbes e, se recebe, que nova interpretação é essa?

Assim, a nosso ver, Hobbes é inovador sob inúmeros aspectos. Um deles é justamente a tese da insociabilidade natural, que o afasta de Aristóteles. Outra inovação é a sua concepção radicalmente nova do conceito de direito natural. Assim, no estado de natureza, o homem encontra-se numa situação de constante conflito, tensão e desconfiança, situação assinalada por uma guerra de todos contra todos. A existência desses conflitos ocorre porque todos têm o mesmo direito e todos são iguais, não havendo um poder superior que possa garantir a segurança. $\mathrm{O}$ conflito, no "Leviatã", tem origem em três causas: competição, desconfiança e busca de glória. Assim, o estado natural é um estado de guerra de todos contra todos e é somente porque esse estado é um estado de guerra que o direito natural se torna direito a todas as coisas. Permanecendo, porém, o direito a todas as coisas, a guerra não poderá findar, por isso é necessária a renúncia a esse direito.

Nesse ambiente é que surge a desconfiança originária. Esse princípio de desconfiança nasce no estado de natureza em virtude da igualdade natural, que se caracteriza como condição da natureza humana. Essa condição se apresenta no estado natural, justamente, porque os homens têm consciência de sua igualdade perante os outros. Assim, como percebem os outros como iguais, desconfiam que eles possam vir a atacá-los, uma vez que entendem que os outros também o percebam como sendo igual. Essa igualdade é fundada na capacidade de uns matarem os outros. Esse conceito é fruto de uma sociedade imaginária, de uma ficção teórica.

É importante frisar que o estado de natureza não é histórico para Hobbes (pelo menos a maior parte dos estudiosos concordam com isso), mas é apenas uma hipótese teórica para pensar como seria um estado no qual se retirasse o poder civil $^{4}$, estado no qual não se encontra uma instituição superior que possa julgar,

\footnotetext{
${ }^{4}$ Evidentemente Hobbes está pensando aqui na guerra civil, pois a Inglaterra passava por uma guerra civil e ele queria demonstrar aos seus contemporâneos os perigos a que ela conduziria.
} 


\section{HUMANAS}

organizar e preservar os direitos de cada indivíduo. Diante disso, procurar-se-á abordar, num primeiro momento, a guerra de todos contra todos, como sinônima dessa desconfiança originária, bem como assinalar o anseio por estabelecer um contrato que possa garantir seguridade a todos.

\subsection{Hobbes: a guerra de todos contra todos e o contrato social}

O estado de natureza de Hobbes se configura pelo direito outorgado pelo próprio indivíduo. Por meio da consciência, o indivíduo adere às leis do soberano em vista da conservação de sua vida, sendo, na verdade, a questão fundamental na filosofia de Hobbes, porque o indivíduo se obriga a ceder o seu "direito de natureza" em ser o próprio juiz, porque é uma maneira de evitar à guerra e viver seguro, tendo em vista a preservação da vida. É importante frisar que a noção de justiça não existe no estado de natureza. Para Hobbes, justiça é o cumprimento dos contratos, e isso somente é possível no estado civil. Também não existe a obrigação efetiva no estado de natureza. Existem as leis naturais, mas elas não obrigam a ações externas, não obrigam efetivamente (Capítulo XV do Leviatã).

$\mathrm{O}$ indivíduo não possui obrigação nenhuma para com os outros e nem encontra justificação para isso por meio da consciência. O que ocorre é que, pelo medo da morte, ele quer sair do estado de natureza. Aqui a razão aponta que o melhor caminho para isso é a paz, sendo esta a primeira lei natural. A razão descobre que o melhor caminho para a paz é fazer um contrato de renúncia ao direito de todas as coisas e viver sob um governo, sendo esta a segunda lei de natureza (Capítulo XIV do Leviatã). Pode-se dizer até que ele tem consciência de algo como obrigação no estado de natureza, mas não uma obrigação perante os outros. Na verdade ele descobre, pela razão, que a melhor maneira de garantir a sua sobrevivência é submeter-se ao soberano. Nesse sentido, a guerra de todos contra todos é uma disposição constante para a luta, mas não é a luta em si, é apenas uma situação que, pela falta de segurança e por meio do princípio da desconfiança, nos levaria o tempo todo a estar preparados para nos defendermos pela luta.

A verdadeira obrigação somente existirá no estado civil, depois do pacto, e nunca no estado natural. Essa obrigação ocorre, então, em relação ao soberano, e não em relação aos outros indivíduos. No estado natural não há um estado maior que possa garantir a segurança, uma vez que as leis naturais apontam apenas para a autopreservação. A lei natural dependerá de cada indivíduo. Sobre essa questão pode-se questionar se é a descoberta da lei que depende do indivíduo ou se é seu cumprimento. Existe uma obrigatoriedade da lei natural no estado de natureza. Hobbes diz que a lei existe, 


\title{
Reconhecimento em Paul Ricoeur: da identificação ao reconhecimento mútuo
}

É.J. Corá \& C.R. do Nascimento

mas é apenas um preceito da razão que aponta o melhor caminho para a paz (cf. capítulo XV do Leviatã) ${ }^{5}$. É no estado de natureza que se caracteriza a possibilidade de igualdade. Nesse sentido, Hobbes escreve que:

\begin{abstract}
[...] Embora por vezes se encontra um homem manifestamente mais forte de corpo, ou de mente mais rápido do que outro, mesmo assim, quando se considera tudo isto um conjunto, a diferença entre um e outro homem não é suficientemente considerável para que qualquer um possa com base nela reclamar qualquer benefício a que outro não possa igualmente aspirar (HOBBES, 2005; p. 74).
\end{abstract}

Para Hobbes (2005), no estado de natureza, os homens possuem certa facilidade de provocar determinado mal aos outros, e é este o fundamento da igualdade. Assim dessa relação de igualdade, as causas da discórdia: a competição, a desconfiança e a glória (a busca por reputação). Quando, por exemplo, existe apenas um objeto a ser distribuído entre os homens e não tendo um reconhecimento de diferença, de sabedoria ou de força entre eles, todos passam a serem iguais e nenhum possui medo do outro. Isso pode ocasionar uma acirrada competição, tendo em vista a aquisição de um determinado objeto. Como não se tem um estado soberano que possa garantir o direito à vida e à propriedade, os indivíduos estão susceptíveis a desenvolver a desconfiança com relação aos outros. Diante disso, na defesa de sua propriedade particular, o indivíduo formula determinados valores para si. Aqui é importante frisar que a vanglória não nasce apenas da defesa da propriedade, mas é uma característica da natureza que aparece na medida em que há o contato com outros.

Cada indivíduo tende a se vangloriar na procura que outros indivíduos contemplem seu valor e que lhe sejam, cada vez mais, atribuídos valores favoráveis. Ao viverem, constantemente, nesse estado de guerra e longe da paz, os homens vivem na tensão diária de que os outros virão tomar o que é seu. Se não se desconfiasse que os outros pudessem atacar, então se acredita que a melhor estratégia, num hipotético estado sem governo, seria resguardar-se a si mesmo, ou seja, permanecer impassível, pois, se se decide atacar, então, os outros podem revidar, desta maneira, se estaria sujeito à morte. Então, a melhor estratégia seria não atacar.

Entretanto, pelo princípio da desconfiança, segundo Hobbes (2005), os homens são levados a pensar que os outros provavelmente atacarão. Então a melhor estratégia é atacar antes do que esperar e ser atacado. O raciocínio de Hobbes nos leva a concluir que devido ao princípio da desconfiança,

\footnotetext{
${ }^{5}$ Há comentadores que tentam apontar que a lei natural em Hobbes é obrigatória no estado de natureza porque é a lei de Deus. Essa tese recebeu o nome de tese Taylor-Warrender (ver: WARRENDER, 1957; POGREBINSCHI, 2003). Atualmente, poucos aceitam a tese Taylor-Warrender.
} 


\section{HUMANAS}

que age em todos, essa não seria a melhor estratégia para a sobrevivência num estado sem governo, isto é, num estado de natureza. Diante disso, um dos pressupostos deste estudo é o de que um estado sem governo desembocaria numa guerra real e o motivo principal disso não é o egoísmo nem a vaidade, como muitos pensam, mas o princípio da desconfiança, que conduz ao tipo de raciocínio probabilístico-estratégico, que se acredita estar na base da argumentação em Hobbes.

O medo é outro conceito central, pois é por consequência dele que os homens atacam, e mais do que é pelo medo que eles procuram sair do estado de natureza. É pelo medo, ainda, que eles saem da situação de guerra e vão ao encontro do estado civil. Hobbes é claro quanto a isso: os homens trocam o medo dos seus companheiros de estado de natureza pelo medo da espada do estado. Nesse sentido, se o soberano impuser o medo a todos no sentido de punir quem não cumpre a lei, o raciocínio probabilístico da desconfiança acaba, porque eu não desconfio mais do outro, já que o soberano irá puni-lo caso ele tente me atacar. Esse se torna o ponto central da filosofia de Hobbes. Assim, o papel do estado é acabar com o princípio da desconfiança e todo o raciocínio probabilístico que ele desencadeia. Diante disso, restam duas escolhas para o homem: sujeição ou liberdade. A primeira escolha conduz à paz, ao progresso e à cultura, enquanto a segunda, à guerra, à vida sórdida, à pobreza e a uma situação desconfortável.

Diante dessa competição há desconfiança e glória, o que é intrínseco ao homem é a vontade de eliminação do outro ${ }^{6}$. Outro pressuposto de ancoragem de nosso estudo é o de que, precisamente, nesse ponto é que ocorre a negação do reconhecimento, porque o outro não é reconhecido pelo que ele é, mas segundo os objetivos de sobrevivência. Para Ricoeur (2006), além da competição e do desconhecimento que, por sua vez, proporcionam a negação do reconhecimento, o estado de natureza conteria em si a antinomia originária entre vaidade e medo da morte violenta ${ }^{7}$. Diante dessa vivência conflituosa e sem paz em que se encontra o homem do estado de natureza, bem como pelo desejo de paz, que é inerente a cada homem, surge a necessidade de estabelecer um contrato que possa garantir a própria vida, bem como a vivência harmoniosa entre os cidadãos.

\subsection{O contrato social: sentido e alcance}

O contrato possui a função de estabelecer um estado de paz em meio a um estado de guerra e de miséria, objetivando colocar fim à guerra.

${ }^{6}$ É importante dizer que nem sempre a vontade é a eliminação do outro, tal como demonstra um texto de Strauss (1968). Geralmente a situação acaba por redundar na tentativa de eliminação do outro.

${ }^{7}$ Novamente, o texto do Strauss tem boas colocações sobre o assunto. 


\section{Reconhecimento em Paul Ricoeur: da identificação ao reconhecimento mútuo}

É.J. Corá \& C.R. do Nascimento

Nesse sentido, o estado de paz permitiria a conservação da vida, bem como certa satisfação, pois as pessoas vivem em constante tensão e medo, enquanto que, com a criação do estado, os homens possuem seus direitos de modo fixo, ou seja, outorgado pelo poder do soberano (HOBBES, 2005).

Por outro lado, para a formação de um estado civil é necessária a união de muitas pessoas. Todavia, submetendo as vontades à vontade do soberano, poderá acontecer uma entrega de direitos (a entrega do direito, a renúncia não é uma possibilidade, mas é o que efetivamente ocorre). Nesse sentido:

[...] Cedo eu transfiro o meu direito de me governar a mim mesmo a este homem, ou a esta assembléia de homens, com a condição de transferires para ele o teu direito, autorizando de uma maneira semelhante todas as suas ações. Pois, todas as pessoas se unem num Estado, o qual é governado pelo soberano, portanto, esse soberano tem três características que são necessárias para ele, a irrevogabilidade, o caráter absoluto e a indivisibilidade (RICOEUR, 2005; p. 103).

Sendo assim, a irrevogabilidade do soberano será condicionada ao apoio do próprio soberano. Assim, não adianta o povo querer entrar em acordo para tirar o soberano, não basta que todos os contratantes tenham esse desejo, pois, em última instância, é necessário que o soberano consinta com isso.

Ainda, de acordo com Ricoeur (2003; p. 2), "a solução é um contrato mas um contrato entre homens atados pelo medo e que se encomenda a um soberano; este não contrata. Não participa como contratante no contrato; tanto que o artifício, o Estado, se apresenta como o animal gordo mencionado no livro de Jó: o Leviatã...". Diante disso, a questão a ser colocada e, ao mesmo tempo, que serve de questionamento a Hobbes e a seus sucessores, é saber se existe um fundamento moral distinto do medo, que possa dar uma dimensão humana à política?

Importante é salientar, neste ponto, o tema da soberania absoluta, em que, após o soberano ter sido instituído, qualquer tentativa de retirá-lo do poder é injusta, porque, a partir do contrato, é o soberano o único que pode julgar a respeito das questões públicas, portanto, qualquer tentativa de tirá-lo do poder sob alegação de mau governo é injusta. O que é contraditório é que somente o soberano pode decidir o que é um bom governo. Por isso, a submissão, em Hobbes, é absoluta e irrevogável e não como, por exemplo, em Locke, para o qual o mau governo serve de justificativa para a revolução. Assim, para que haja dissolução do contrato, o soberano deve estar em concordância para derrubar a si mesmo do poder. A propósito lê-se: 


\section{HUMANAS}

[...] Dado que o direito de representar a pessoa de todos é conferido ao que é tornado soberano, por um acordo feito apenas entre cada um e cada um, e não entre o soberano e cada um dos outros, não pode haver quebra do acordo da parte do soberano, portanto nenhum dos súditos pode libertar-se da sujeição, sob qualquer pretexto de transgressão (HOBBES, 2005; p. 104).

O que se percebe é que não há possibilidades de quebra de contrato, uma vez que o soberano é absoluto ${ }^{8}$. Desse modo, Hobbes garante a soberania absoluta e nada do que o soberano faça pode ser considerado injusto, pois injustiça é apenas a quebra de contratos. No estado civil, o soberano é absoluto porque somente ele tem o direito sobre todos. Caso contrário, ele seria súdito. Para Hobbes (2005), nessa maneira de governo, caso ocorra um desacordo de ideias, tornar-se-ia uma anarquia e, consequentemente, uma guerra civil, por conseguinte, o retorno ao estado de natureza.

Analisadas as evidências do contrato social percebe-se o abandono de direitos como "renúncia e transferência". Além disso, em Ricoeur (2006) os termos "recíproco e mútuo" recebe outra perspectiva, não mais se apresentando em conformidade com a guerra, mas com o objetivo de uma busca pela paz. Diante disso, o abandono dos direitos naturais que são próprios dos indivíduos não requer reciprocidade, mas um dom. Entende-se, diante da análise ricoeuriana, relativa ao estado de natureza e ao contrato social hobbesiano, que já se encontra prefigurada certa desconfiança originária, que se realiza na própria característica natural do homem de defender o que é seu.

\section{O reconhecimento mútuo}

Segundo Ricoeur, Hobbes foi o adversário que a filosofia política tentou combater, e Hegel estaria entre aqueles que lhe fizeram oposição. A questão que se coloca a partir de Hobbes é buscar compreender se há um fundamento moral diferente daquele que o medo representava, ou seja, um fundamento que fosse capaz de fornecer um aspecto humanista à filosofia política. Conforme Ricoeur (2004, p. 12-13), é nessa direção que Hegel se coloca, mas ele estaria apoiado por três posições contrárias a Hobbes, que em alguma medida o anteciparam,

\footnotetext{
${ }^{8}$ A quebra de contrato, por parte do soberano, nunca ocorre, porque ele não contrata com os súditos. Esse é o ponto fundamental que distingue Hobbes de outros contratualistas, como Locke, por exemplo. Porque se o soberano fizesse um contrato com o povo, como ocorre em Locke, qualquer ação que seja contra o contrato necessariamente é uma quebra de contrato e justifica, por exemplo, a rebelião.
} 


\section{Reconhecimento em Paul Ricoeur: da identificação ao reconhecimento mútuo}

É.J. Corá \& C.R. do Nascimento

quais sejam: a) a ideia de uma marca moral originária a partir da qual se pode possuir, fazer e agir (Grotius); b) a ideia de autonomia, onde o si e a norma apresentam um vínculo originário, porém haveria aí o problema de como fazer derivar uma filosofia política do princípio de autonomia (Kant); c) a ideia de reflexão sobre si vinculada a ideia de reflexão sobre o outro (Fichte).

Em Hegel, a origem da política não reside no medo, como em Hobbes, mas através do que Ricoeur caracteriza como um impulso espiritual da negatividade que produz instituições que se organizam em torno à família, à sociedade e culminam com a sociedade política (RICOEUR, 2004, p. 12-13). Por sua vez, Ricoeur interessou-me pelo que se chama de reapropriação e atualização dos argumentos de Hegel no que tange às experiências do desprezo, pois:

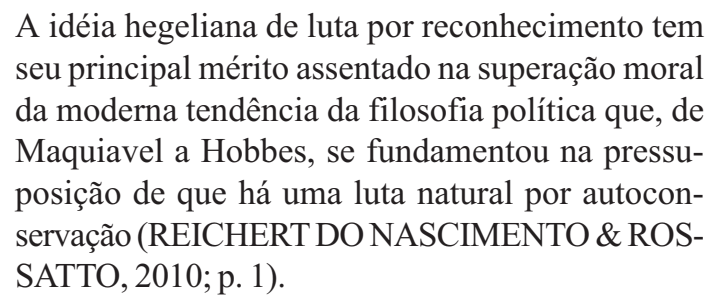

Tal reapropriação e atualização levadas em conta pelo filósofo francês são feitas por Honneth. $\mathrm{O}$ desejo de ser reconhecido nasce das experiências do desprezo (Missachtung), e, na análise de Honneth, ele está num nível que não é pré-jurídico ou pós-jurídico, na verdade, situa-se entre eles, a saber, o desprezo social, que é a nova forma de negação. É justamente essa aproximação entre o desprezo e o reconhecimento na figura do desprezo social que Ricoeur julga ser o mérito desta reatualização.

O desprezo social é uma mazela da sociedade civil, a qual "marcada essencialmente pela industrialização... produz ao mesmo tempo a pobreza" (RICOEUR, 2004; p. 19). É justamente sob esse ponto que Ricoeur vai expor uma das questões mais pertinentes ao debate contemporâneo no âmbito sociopolítico que é o vínculo "estranho" entre a produção de riqueza e a produção de desigualdades. Ao invés da produção de riqueza gerar a promoção de igualdade, no mais das vezes, ela gera a produção de desigualdades porque a riqueza é geração de mais dinheiro que, por sua vez, acentua a diferença entre àqueles que o têm e os que não o têm.

A produção de desigualdade pelo dinheiro é "fonte de desprezo [desconhecimento], negação de reconhecimento" (RICOEUR, 2004; p. 19), exibindo a maior contradição existente em nossas sociedades, entre a atribuição igualitária de direitos e a desigualdade na distribuição dos bens. É aí que se encontra o desprezo entre os níveis pré e pós-jurídico, porque, por mais que, atualmente, países como o Brasil tentem reduzir essa contradição por meio do aparato legal de redistribuição de renda, 


\section{HUMANAS}

apontado, por exemplo, por Thomas Nagel (2007; p. 86) como uma maneira de superar as desigualdades decorrentes das diferenças de classes, ela continua a existir. Ou seja: por mais que se tente reduzir o hiato entre a igualdade de direitos, por exemplo, assegurada pela constituição de uma nação, e a desigualdade de bens, não é a expansão daquela que vai eliminar esta completamente. Nesse sentido, a afirmação de Ricoeur $(2004$; p. 20) é capital para corroborar o que dissemos: "não sabemos produzir sociedades econômica e socialmente igualitárias, ao passo que a fundação jurídica de nossas sociedades é o direito igual de acesso a todas as fontes do reconhecimento jurídico".

Desse modo, o indivíduo que, por um lado, é reconhecido juridicamente, por outro lado, não é reconhecido socialmente, sofrendo, conforme Ricoeur, de um desprezo fundamental. Observa-se que distribuição de direitos que se exprime na igualdade de direitos, geralmente assegurada pelas constituições dos estados nacionais, não acontece do mesmo modo quando se trata da distribuição de bens. Aí existe uma clara assimetria entre o reconhecimento jurídico e o reconhecimento social. A partir dela é que Ricoeur vai pensar se haveria em nossas relações sociais uma maneira de reconhecimento não violento face ao reconhecimento conflituoso posto sob a ideia hegeliana de luta por reconhecimento.

Ao invés de afirmar as experiências de reconhecimento sob a ideia de luta, Ricoeur propõe o reconhecimento pela ideia de dom, trazida à publico por Marcel Mauss por meio de seus estudos sobre as sociedades arcaicas. Em Essai sur le don. Forme et raison de l'échange dans les sociétés archaïques, Mauss descreve a existência de sistemas de troca entre os nativos tribais, como os Maori, que uns aos outros dão presentes, os quais devem posteriormente ser trocados ou devolvidos. Para Mauss, o grande enigma não era porque se dá algo a outrem, mas porque era preciso retribuir o dom recebido. A explicação estava no fato de acreditar na existência de uma força mágica que acompanhava o dom e devia retorna à sua origem.

Na retomada que Ricoeur faz da obra de Mauss, não é tão relevante que aquele que recebeu o dom esteja obrigado a restituí-lo. Antes de tudo, o que importa é que na atitude de dar o dom, aquele que da reconhece quem o recebe. E mesmo que o donatário venha a dar em troca, ou seja, venha a restituir o dom ao doador, esse ato será como o primeiro ato de doação e não como o segundo ato, ou seja, não se trata de restituição do dom. Ao invés de afirmar a ideia de uma força mágica que deve volta à origem, ele concordará com a interpretação que Marcel Hénaff preconiza, a saber: o reconhecimento tácito. Não importará o que é dado àquele que é reconhecido.

$\mathrm{Na}$ verdade, o que tem de ser frisado é que o doador se dá ele próprio quando oferece um presente, um regalo (RICOEUR, 2004; p. 23-4). Ocorre o deslocamento da ideia do "dom" como força mágica para o "dom" como a representação do reconhecimento tácito. A hipótese levantada por Ricoeur é que o ato 
mútuo de reconhecer o outro por meio da gestualidade do dom é que gera um reconhecimento simbólico através da coisa dada, assim, sem a existência de conflito e sem violência. Portanto, o reconhecimento mútuo é simbólico, pois o "dom" simboliza o doador e o destinatário dele.

Afinal, é possível o reconhecimento mútuo ou ele é uma utopia? Este é o mote do recente artigo de Gonçalo Marcelo (2011) intitulado Paul Ricoeur and the utopia of mutual recognition. Marcelo claramente defende que o reconhecimento mútuo é uma utopia, mas longe de se tratar de uma crítica a Ricoeur é uma leitura que nos parece perfeitamente adequada. O que torna correta essa interpretação é a observação de que o reconhecimento está assentado no núcleo da chamada petite éthique, qual seja: "o desejo de uma vida realizada com e para os outros em instituições justas". Se considerarmos essa frase por partes percebemos que ela é composta por uma tríade ética, como o próprio filósofo francês afirma, ("o desejo de uma vida realizada" "com e para os outros" “em instituições justas"), na qual o ser humano aspira uma vida boa, leia-se, uma vida realizada, porém ela só pode ser buscada se além de haver a auto-estima ou estima de si, houver a estima e o respeito pelo outro, e por último, as sociedades em que vivemos são consideradas como instituições, e elas fundam estas com as mais diversas configurações. Deve ser destacado que é na estima pelo outro que se enquadra este arranjo para o reconhecimento, além do mais, a estima pelo outro vai de encontro à estima de si como narcisismo. Na verdade, aquele que estima uma vida realizada estima o outro, seja na manutenção da promessa dada ou no ato de reconhecimento.

\section{Considerações finais}

Em "Percurso do reconhecimento" (2006), Ricoeur avança em relação às suas obras anteriores, caracterizando as formas possíveis de reconhecimento que o indivíduo pode obter por parte da sociedade em que vive. Esse reconhecimento pode ser organizacional ou institucional, gerando o prestígio, a consideração e a aceitação. Viver em comunidade exige um esforço contínuo de reconhecimento dos outros e de busca por ser reconhecido.

Aceitar as diferenças pode facilitar o reconhecimento do outro, mas pode também, por um lado, banalizare, por outro, torná-los tão evidentes que o reconhecimento vem acompanhado da intolerância' ${ }^{9}$. Como então encontrar o caminho correto?

\footnotetext{
${ }^{9}$ Partindo de uma releitura do mito babélico, regido pela consciência da linguagem como testemunho irrecusável da condição finita e carnal do homem e da tradução como paradigma hermenêutico da mediação entre mundos culturais diferentes, chegamos então à necessidade de elaboração de uma teoria e de uma prática da hospitalidade... Nessa perspectiva, o remédio contra a intolerância não poderia ser um sincretismo superficial ou o chamado aos bons sentimentos, mas um aprofundamento de nossas raízes espirituais, que nos tornam capazes de escutar e de dialogar com o outro, com o estrangeiro que pode, então, tornar-se o amigo, o anfitrião, aquele que guarda uma semente de verdade que nos falta e que integra o fragmento que nos possuímos ou acreditamos possuir (JERVOLINO, D. Texte a été présenté à l'Université Charles de Gaulle - Lille3, le 4 mars, pp. 9-10, 1999, tradução dos autores).
} 


\section{HUMANAS}

As experiências de reconhecimento mútuo podem fornecer, ainda que provisoriamente, uma solução ao dilema, ainda que a condição estabelecida seja "eu te reconheço por que (e somente porque) você me reconhece". A solução parece ser encontrada entre a boa vontade, caracterizada pelo amor incondicional que permite a compreensão e, por outro, a efetivação operacional da justiça, enquanto norma.

Por último, outra questão importante, que foi tematizada ao longo deste trabalho, diz respeito ao conceito de reconhecimento, que, em efeito, suscita, hodiernamente, um novo interesse, tanto no âmbito ético quanto político, uma vez que pressupõe a esfera intersubjetiva. A diferença estabelecida por Ricoeur entre a ética e a moral se encontra, então, transposta no tema da intersubjetividade. Como vimos, o desejo de ser reconhecido desempenha um papel determinante no "querer viver em conjunto" do homem. Assim, foi possível verificar que no "querer viver em conjunto", o desejo e a luta pelo reconhecimento, pode ser tomado como substituto do medo de uma morte violenta e da luta pela sobrevivência, que caracterizam a condição natural do homem descrito por Hobbes.

Nesse sentido, por meio do reconhecimento mútuo é possível estabelecer uma passagem do desconhecimento originário presente na teoria política hobbesiana, acentuadamente marcada pela competição, pela desconfiança e pela glória, para o estabelecimento de uma relação despreocupada, desinteressada, isto é, não marcada pelo viés da preocupação em dar para esperar a retribuição, mas firmada pela característica de abundância do coração, ou seja, dar sem a preocupação de ser retribuído, do reconhecer não pelas categorias que "eu" estabeleço, mas pelo que o outro se apresenta. É por isso que a obra de Ricoeur inaugura um novo capitulo nas relações interpessoais e na maneira de tratar o tema do reconhecimento na atualidade.

\section{Referências bibliográficas}

GREISCH, J. Vers quelle reconnaissance? Revue de Métaphysique et de Morale, v. 2, n. 50, 2006.

HEGEL, G. Fenomenologia do espírito. Trad. Paulo Menezes. Petrópolis: Vozes, 2002.

HOBBES, T. Leviatã. Trad. Heloisa da Graça Burati. São Paulo: Rideel, 2005.

HONNETH, A. Luta por reconhecimento: a gramática moral dos conflitos sociais. São Paulo: Editora 34, 2008.

JERVOLINO, D. Le Parole della Prassi: Saggi di ermeneutica. Napoli: Città del Sole, 1996a. 


\section{Reconhecimento em Paul Ricoeur: da identificação ao reconhecimento mútuo \\ É.J. Corá \& C.R. do Nascimento}

JERVOLINO, D. La reciprocita dei soggetti come principio etico-politico. In: Le Parole della Prassi: Saggi di ermeneutica. Napoli: Città del Sole, 1996b.

MARCELO, G. Paul Ricoeur and the utopia of mutual recognition. Etudes Ricoeuriennes/Ricoeur Studies, Pittsburgh, v. 2, n. 1, 2011.

NAGEL, T. Uma breve introdução à filosofia. São Paulo: Martins, 2007.

POGREBINSCHI, T. O problema da obediência em Thomas Hobbes. Bauru: EDUSC, 2003.

REICHERT DO NASCIMENTO, C., ROSSATTO, N. D. Reconhecimento simbólicoedom. Éthic@, v. 9, n. 2,2010.

RICOEUR, P. Percurso do reconhecimento. São Paulo: Loyola, 2006.

RICOEUR, P. Le Juste, la justice et son échec. In: M. REVAULT \& F. AZOUVI (Orgs.). Les Cahiers de L'Herne. Pp. 287-306. Paris: Éditions de l'Herne, 2004.

RICOEUR, P. Le conflit des interprétations: essais d'herméneutique. Paris: Seuil, 1969.

RICOEUR, P. La lutte pour la reconnaissance et l'économie du don. Paris: Unesco.

RICOEUR, P. Connaissance de soi et éthique de l'action. Sciences humaines, 63: 34-8, 1996 .

RICOEUR, P. Soi-même comme un autre. Paris: Seuil, 1996.

ROSSATTO, N.D. Viver bem: ética e justiça. Mente, Cérebro \& Filosofia. Presença do outro e interpretação: Ricoeur, Gadamer, São Paulo, v. 11, p. 2633, Jul., 2008.

SALDANHA, F.A.M. Do Sujeito capaz ao sujeito de direito: um percurso pela filosofia de Paul Ricoeur. Tese de Doutoramento em Filosofia. Coimbra: Faculdade de Letras, Universidade de Coimbra, 2009.

STRAUSS, L. Natural right and history. Chicago: The University of Chicago, 1968.

WARRENDER, H. The political philosophy of Hobbes. Oxford: the Clarendon Press, 1957.

WILLIAMS, R.R. Ricoeur on recognition. European Journal of Philosophy, New York, v. 16, n. 3, 2008. 